\title{
Clasmatothenesis, A New Type of Amitotic Nuclear Division in Striated Muscle Cells of Insects
}

\author{
Tomás P. Pessacq \\ Instituto de Investigación de Ciencias Biológicas \\ Montevideo, Uruguay
}

Received May 18, 1968

\section{Introduction}

The existence of different forms of amitotic nuclear division in vertebrate skeletal and cardiac striated muscle tissue has been demonstrated in a series of microscopical studies (Stemmler 1928, Tower 1939, Altschul 1942, 1946, Le Gros Clark 1946, Linzbach 1947, Grundmann 1950, 1963, Hort 1953). In general, these studies suggest that amitotic nuclear division occurs as a process of constriction or fissuration in enlarged nuclei without formation of mitotical apparatus. The increase in size of amitotically dividing nuclei may be considerable. Separation may be complete or neighboring nuclei may be connected by a thin filament. Stemmler (1928) observed nuclei 20 times longer than normal in damaged skeletal muscles. If this increase occurs mostly along the long axis, as it usually does, the nuclei are spoken of as nuclear rods and by dividing amitotically into two or more fragments, nuclear chains originate consisting of several nuclei in close contact. This can be frequently observed in regenerating mammalian skeletal muscle fibers (Altschul 1946).

A study of some problems of comparative histology of muscle fiber differentiation led us to discover some interesting nuclear structures and nuclear arrangements in insect muscle fibers that appear to constitute a clear example of amitotic nuclear division which have not been described before. The purpose of this paper is to present the morphological evidence for this form of nuclear division and to present evidence for a new cellular structure, called by us as polykaryonema, which represents the morphological pattern found in the early stage of nuclear division.

\section{Material and methods}

Adult specimens and embryos of Musca domestica, Polybia scutellaris White, Photinus fuscus and Acromyrmex lundi were used. Microscopical preparations were performed by two different methods:

A) Fragments of the insect tissue were placed in a centrifuge tube and homogenized lightly by means of a glass rod and then the tissue pulp was suspended in $5 \mathrm{ml}$ distilled water. The suspension containing the isolated 
cells and tissue fragments was collected and centrifuged at $10(10$ r.p.m. for 3 minutes. The supernatant was aspirated off. Methanol-glacial acetic acid $(3: 1)$ fixative was added without disturbance of the pellet at the bottom of the centrifuge tube. After 2 hours' fixation the cells were suspended, centrifuged and resuspended in fresh fixative. Slides were prepared by the air-drying technique on Rothfelds and Siminovitch (1958).

B) Fragments of flight muscle were carefully excised, placed, in albumenized slides, squashed and fixed for 15 minutes in Carnoy's fluid. The smears obtained by these two methods were stained with Feulgen, Giemsa and toluidine blue stainings and with a modification of Estable's silver method for the slight staining of nucleolonema (Estable and Sotelo 1951, 1952).

\section{Results}

Nuclei are arranged in rows along the central axis of the fiber in striated
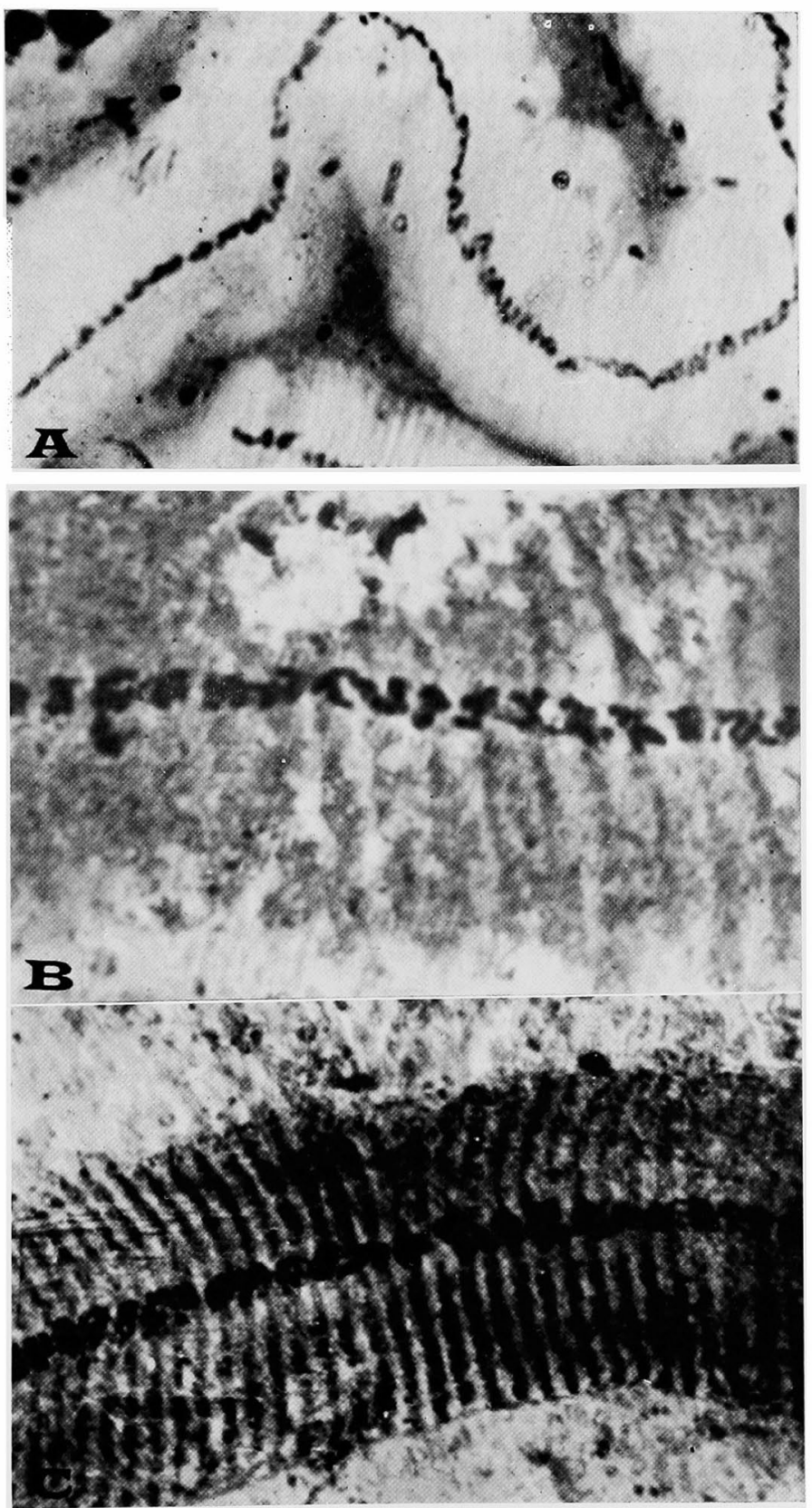

Fig. 1. A, central row of nuclei in a young muscle cell of Acromyrmex lundi. Feulgen staining. $\mathrm{B}$, and $\mathrm{C}$, central rows of nuclei in close contact and partially fused in striated muscle cells of Polybia scutellaria White. Estable's silver method slightly modified. A. $450 \times$; B and C. about $2500 \times$. Muscle cell cytoplasm. 
muscle fibers of adult insects. The distance separating the nuclei varies considerably and depends on the degree of evolution of the fiber. Well differentiated fibers possess a wide sacroplasm and clear striations have nuclei separated by $10-15 \mu$. In these cases nuclear chromatin presents a spongy
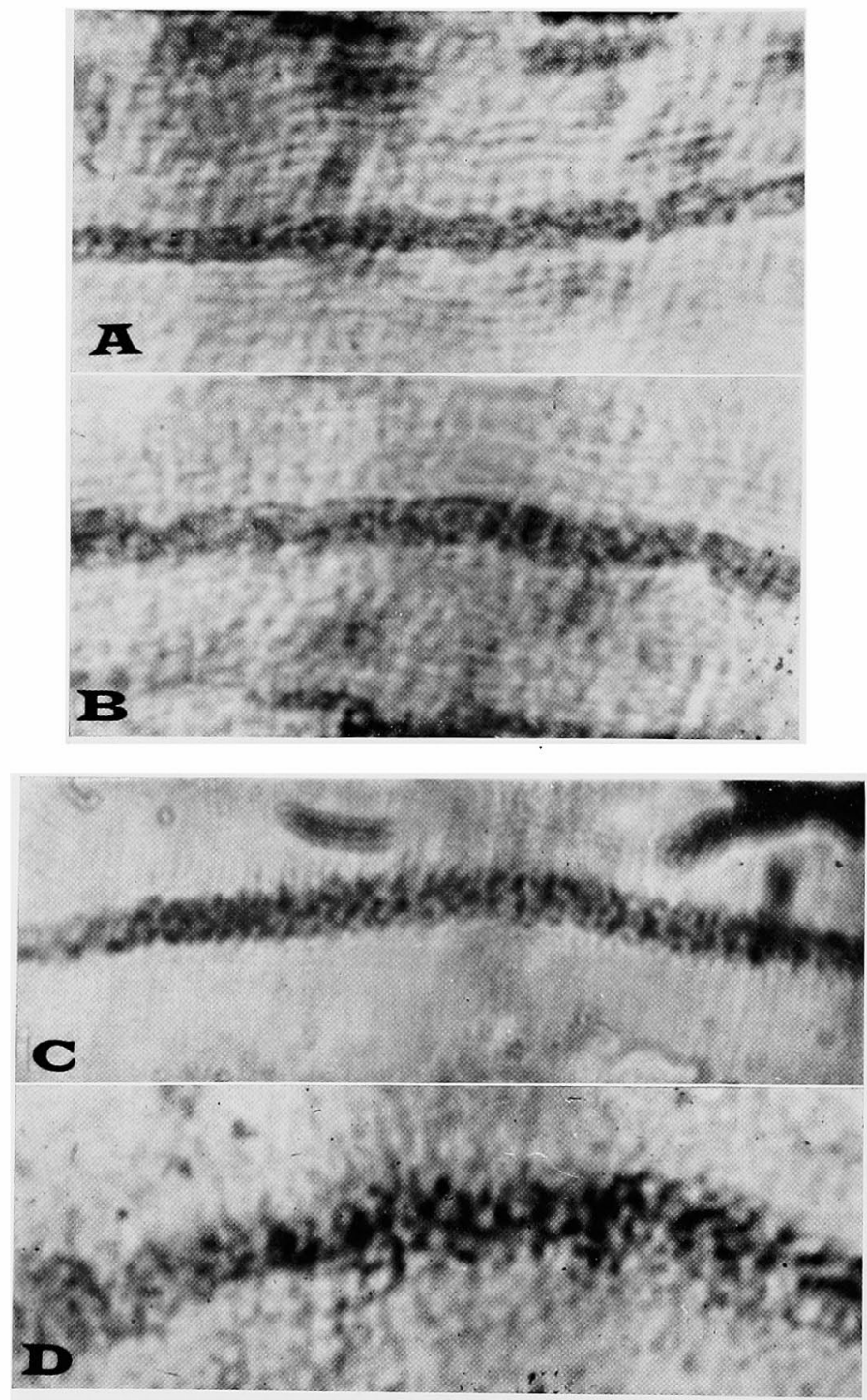

Fig. 2. A, and B, continuous chromatinic cord (Polykaryonema) in myoblasts of an adult specimen of Photinus fuscus. Note the presence of tenuous longitudinal striations in the cytoplasm. $\mathrm{C}$, and $\mathrm{D}$, chromatinic cords in myoblasts of an adult specimen of Acromyrmex lundi. Feulgen staining. About $3000 \times$. reticulate structure.

On the other hand the nuclei are usually in closer contact forming long chains in incompletely differentiated muscle fibers and frequently show clearcut commissures connecting two or more adjacent nuclei. Moreover it was possible to observe the existence of an extremely thin filament extending for a variable distance among two or more adjoining nuclei at high magnification. In most cases this interesting structure is intensely Feulgen positive throughout its length. In other cases the chromatinic commissures had a somewhat different aspect and do not appear as a deeply stained homogeneous filament. They appear rather as a chain of intensely Feulgen positive granules alternating with segments that were lightly stained. Mayer's haemalum, Heidenhain's iron hematoxylin, toluidin blue and special silver procedures give essentially the same results as the Feulgen reaction. Never- 
theless, nuclei in other zones of the chain may retain their individuality.

In young specimens of the studied insects, long, continuous nuclei were observed. This arrangement was constantly observed in myoblasts and in inmature muscle cells in which transverse striations were not clearly evident. In the place of nuclear rows there is a single continuous nuclear structure which extends almost the entire length of the cell and is usually located along its central axis. The maximum diameter of this nuclear cord-like structure is $5-6$ microns and is therefore similar to that of an isolated nucleus of the adult muscle fiber it may range to as little as $1-11 / 2$ microns and show its typical filamentous aspect (Fig. 1A and B).

Because of its distinctive morphological appearance and its ability to give rise to rows of individual central nuclei of more differentiated muscle fibers by successive divisions, it seems logical to recognize it as a distinct entity. Therefore we propose the term polykaryonema to designate this nuclear structure. In summary, insect striated muscle cells show an interesting process of nuclear division during the course of differentiation.

It is possible to schematically outline the behaviour of nuclear structures during
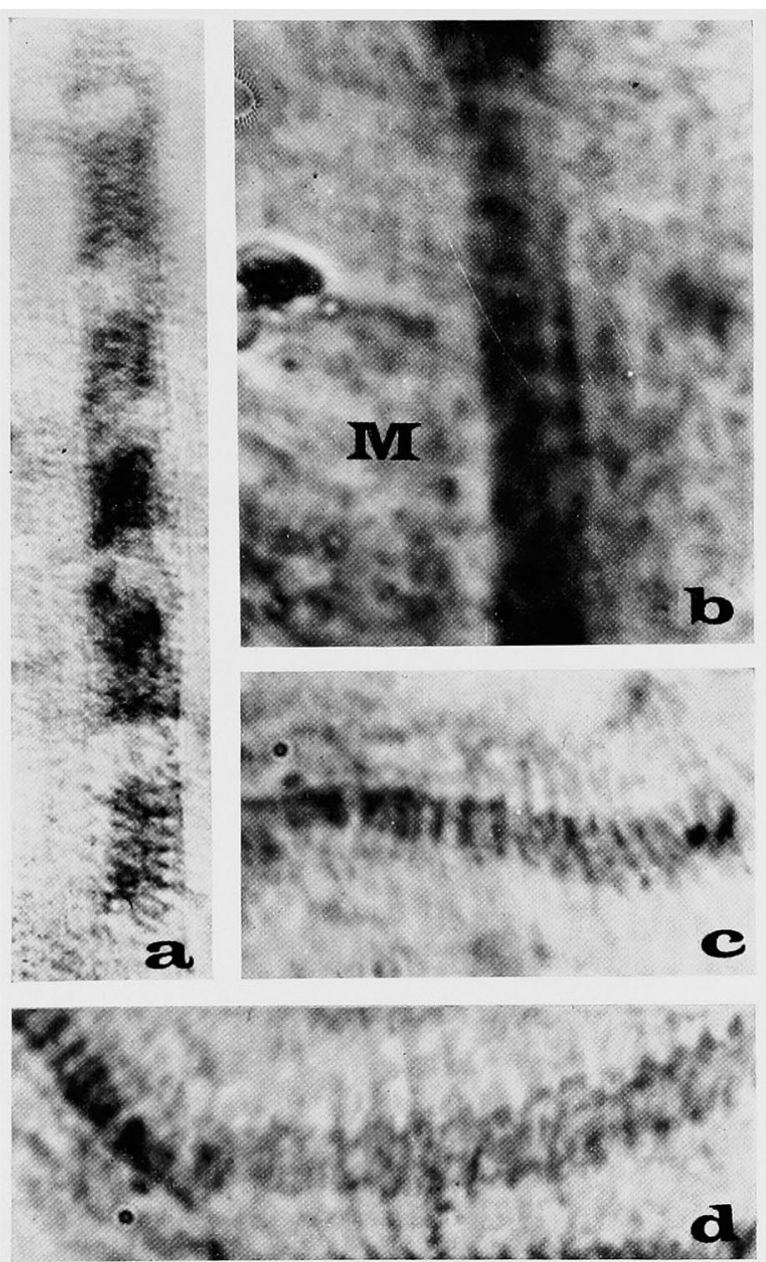

Fig. 3. a, b, c, and d, different aspects showed by the chromatinic cords in the myoblasts of larvae of Musca domestica. Note in $\mathrm{b}$ the presence of longitudinal striations in the cytoplasm. Toluidine blue staining. -Mmuscle cell cytoplasm. About $3000 \times$. the different stages by which myoblasts differentiate into adult muscle cells.

1. Nuclei grow longitudinally by a process of endomitosis (Geitler 1953) to form a polykaryonema (Fig 2).

2. Nuclear strands develop which are constituted by several parallel filaments or by a series of granules (Fig. 2D). 
3. Nuclear chains appear in which the dividing nuclei remain connected by chromatinic filaments (Fig. $1 \mathrm{~A}$ and $\mathrm{B}$ ).

4. Nuclear rows remain which are constituted by isolated nuclei.

Evidence against artifactual contacts and superposition among isolated
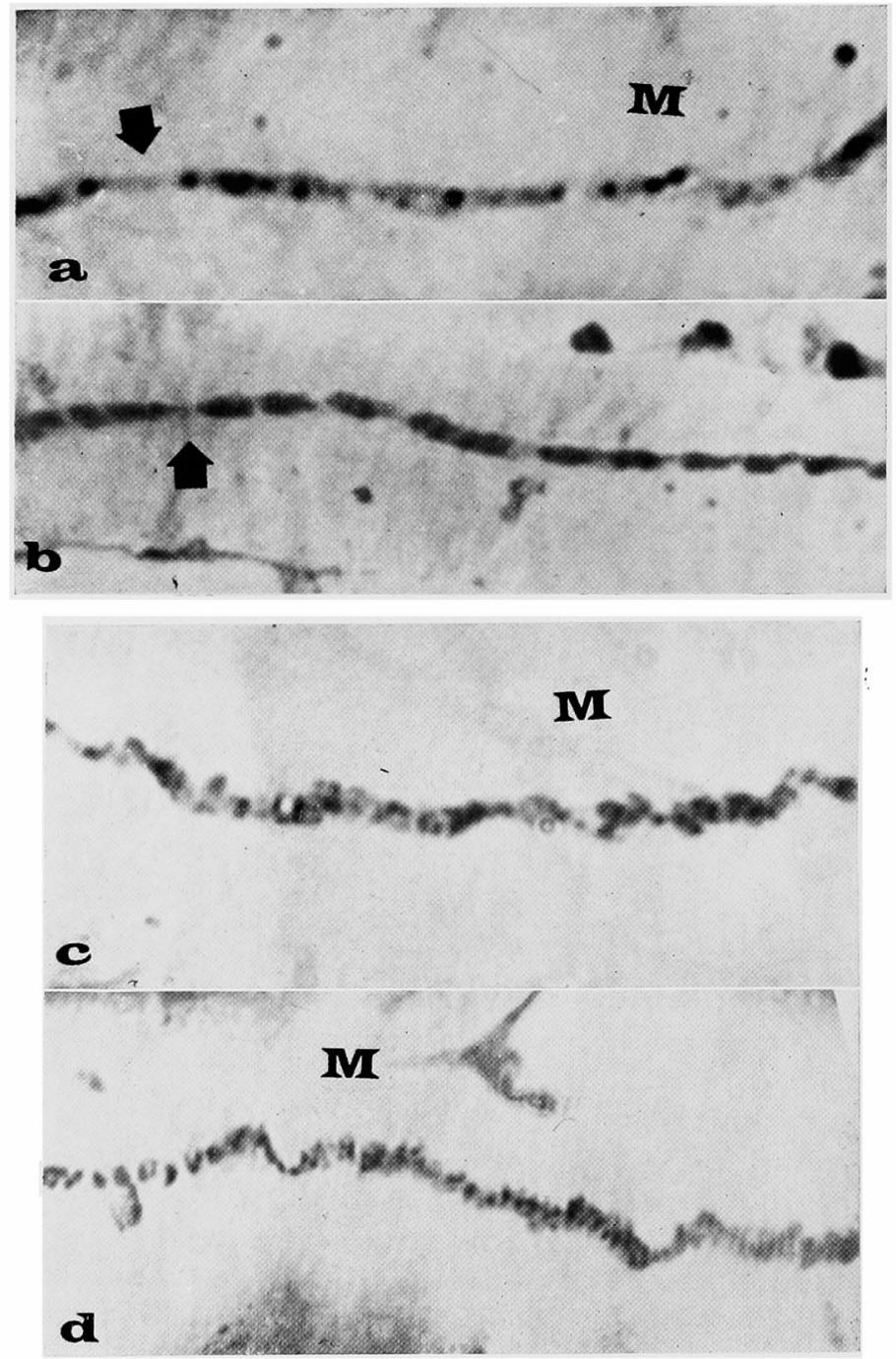

Fig. 4. Different types of Polykaryonema. a, and b, immature muscle cells of Dermatobia cyaniventria Macquart. -M- muscle cell cytoplasm. The arrows show extremely thin filamentous segments of the chromatinic cord. c, and d, immature muscle of Acromyrmex lundi. a, and b, toluidine blue staining. b, and c, Feulgen staining, about $3000 \times$. central nuclei produced by shortening of the muscle cells does not appear likely because of the presence of clear cut commissural chromatinic filaments as seen in Figs. 4a and b, and from the persistence of such uninterrupted strands in preparations in which stretching artifacts have been carefully avoided by immersing muscle tissues in insect Ringer to which the fixative was gradually added.

\section{Discussion}

The serially changing morphology of the nuclear apparatus of striated muscle cells represents a type of amitotic nuclear division accompanying the differentiation of primitive mononucleated myoblastic elements.

We can reconstruct the process as follows: The myoblastic nuclei that differentiate into macronuclei anlagen enlarge longitudinally to several times their original size with an accompanying loss of staining capacity (Fig. 2). Iron hematoxylin preparations reveal the presence of granular filaments within 
the cytoplasm at this time which correspond to newly formed myofibrils. These filaments become more numerous and stain more intensely during the later stages. As differentiation continues, the elongated macronucleus increases in size and develops a filamentous and cord-like form. When this condition is reached, it begins to divide near its extremities by constricting into dumbbell-shaped bodies. These newly formed nuclei remain connected to one another and to the original nuclear structure (polykaryonema) by thin chromatinic strands. The elongated giant nuclei continue to divide into smaller independent nuclei until a typical nuclear chain is formed. In most cases division of the polykaryonema is transverse, but longitudinal divisions of this structure may also be observed. Double nuclear chains may thereby develop as the one appearing in Fig. 5A and B.

The most characteristic feature of this process is multiple fragmentation

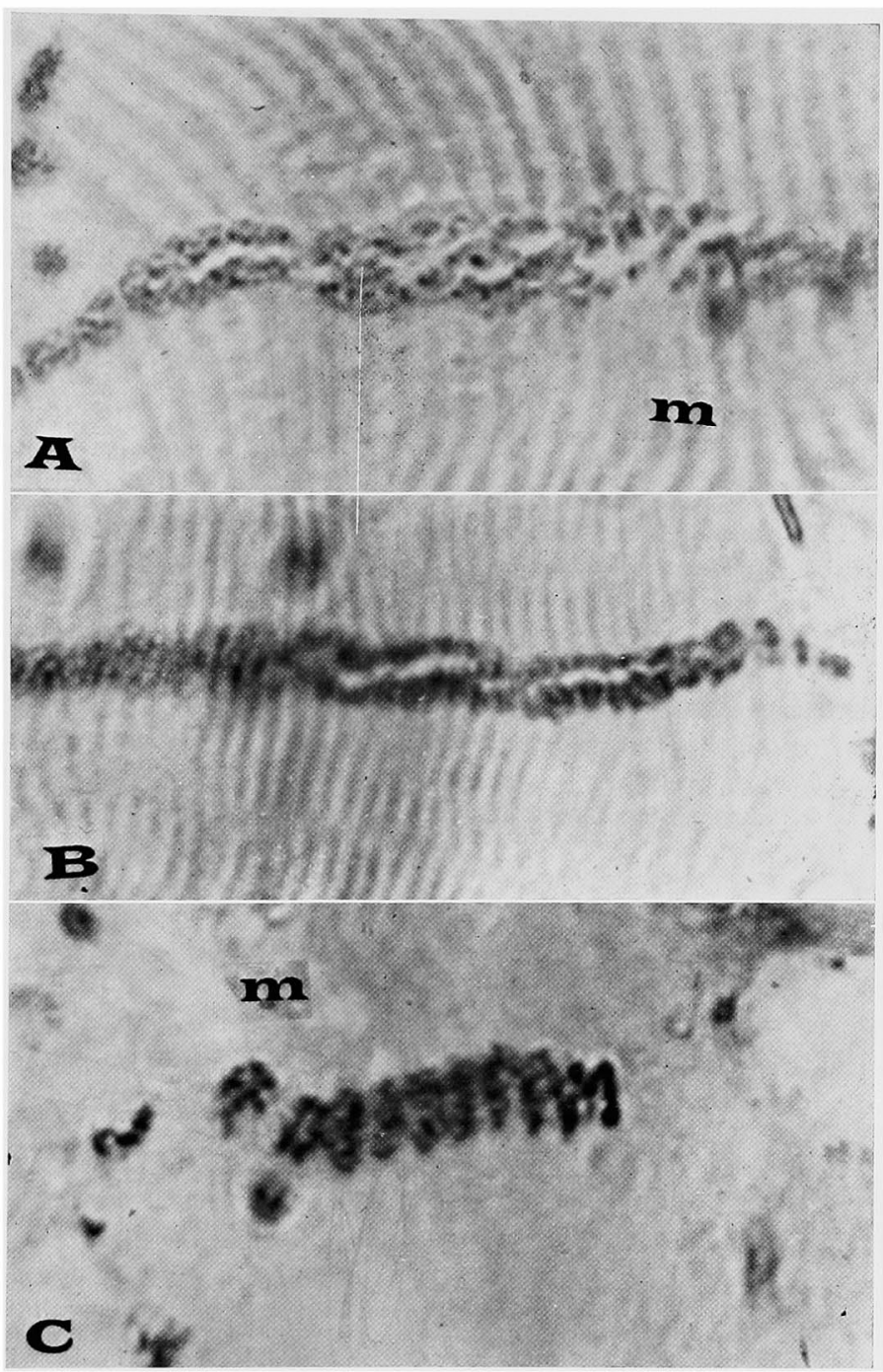

Fig. 5. A, and B, longitudinal division of the chromatinic cord. Note the presence of transverse striations. C, helicoidal arrangement of the polykaryonema in a myoblast. -m- muscle cell cytoplasm. Adult specimen of Polybia scutellaria White. Feulgen staining. About $3000 \times$.

of a chromatinic body (polykaryonema) which generates a row of independent nuclei and we propose the term Clasmatotenic division or simply Clasmatotenesis to designate this form of amitotic nuclear division. These findings hopefully will enlarge the concept of amitotic division and seem to support 
and extend the concept of direct nuclear division as a normal process in invertebrate tissue.

\section{Summary}

A new type of amitotic nuclear division in differentiating striated muscle cells of insects (Dermatobia cyaniventris Macquart, Polybia scutellaris White, Photinus fuscus and Acromyrmex lundi) is described. It consists of a process of multiple fragmentation of a single chromatic cord, a sort of giant longitudinal macronucleus which extends almost the entire length of the immature muscle cell. We have designated this interesting nuclear structure as polykaryonema and this amitotic nuclear division process as clasmatothenesis.

\section{References}

Altschul, R. 1942. Atrophy, degeneration and metaplasis in denervated skeletal muscle. Arch. Pathol. 34: 982-988.

- 1946. Nucleosis of skeletal muscle. Science 103: 566-567.

Estable, C. and Sotelo, J. R. 1951. Una nueva estructura celular: el nucleolonema. Inst. Invest. Cien. Biol. Publ. Montev. 1: 105-126.

- 1952. Technical procedures for the study of the nucleolonema. Stain Technol., Geneva, N. Y. 27: 307-312.

Geitler, L. 1953: Endomitose und endomitotische Polyploidisierung. Protoplasmotologia $\mathrm{VI} / \mathrm{c}$ Springer, Wien.

Grundmann, E. 1950. Histologische Untersuchungen über die Wirkungen experimentellen Sauerstoffmangels auf das Katzenherz. Beitr. path. Anat. 111: 36-76.

- 1963. Allgemeine Cytologie, eine Einführung in die funktionelle Morphologie der Zelle. Ed. G. Thieme, Verlag, Stuttgart.

Hort, W. 1953. Quantitative histologische Untersuchungen an wachsenden Herzen. Virchows Arch. path. Anat. 323: 223-242.

Le Gros Clark, W. E. 1946. An experimental study of the regeneration of mammalian striped muscle. Jour. Anat. 80: 24-36.

Linzbach, A. J. 1947. Mikrometrische und histologische Analyse hypertropher menschlicher Herzen. Virchows Arch. path. Anat. 314: 534-594.

Rothfels, K. H. and Siminovitch, L. 1958. Stain Technol. 31:247. (As cited by R. C. Hard and B. Kullgren in Chimetric Mice with Donor-Type Liver Cells, Science 152: 349,1966$)$.

Stemmler, M. 1928. Uber physiologische Regeneration und Gewebsverjüngung. Beiträge zür pathologischen Anatomie und zür allgemeinen Pathologie 80: 512-569.

Tower, S. S. 1939. The reaction of muscle to denervation. Physiol. Rev. 19: 1-48. 